\title{
Clinical Reasoning: Importance of clinical phenomenology in the era of genetic testing
}

Meera R. Basu, BA, Alberto J. Espay, MD, MSc, Emily G. Wakefield, BS, MS, LGC, and Steve W. Wu, MD

Neurology ${ }^{\circledR}$ 2018;90:e534-e537. doi:10.1212/WNL.0000000000004930
Correspondence

Dr. Wu

steve.wu@cchmc.org

\section{SECTION 1}

A 13-year-old right-handed girl had abnormal involuntary movements since infancy. She was born full-term by vaginal delivery with birthweight of 8 pounds, 3 ounces, from a mother who smoked cigarettes. The delivery was complicated by meconium aspiration but she did not require intubation or intensive care. Throughout her life, the abnormal movements remained stable. She described these movements as involuntary, nonsuppressible shaking, involving her entire body. The movements were continuous throughout the day, without diurnal variation, resolved only during sleep, were exacerbated by anxiety and excitement, and caused frequent falls. Medication trials with baclofen and levodopa were ineffective. She had history of global developmental delay (GDD), intellectual disability (ID), and adjustment disorder with anxiety, treated with sertraline. She also had intermittent asthmatic exacerbation and insomnia.

The patient's parents were deceased at the time of assessment. Her paternal grandmother, who had difficulty walking as a child but denied any ongoing neurologic symptoms, provided limited history. Her father reportedly had involuntary movements since early infancy with motor delay, inattentive symptoms, and frequent falls, and carried a presumed diagnosis of cerebral palsy. $\mathrm{He}$ died of lung cancer at age 41 years. Her mother had multiple sclerosis and died in early adulthood, reportedly from myocardial infarction. The patient was enrolled in 7 th grade under an individualized educational program.

Neuropsychological evaluation revealed low-average to average intelligence, very low to lowaverage performance in verbal fluency, average working memory, and poor fine motor skills. Neurologic examination (video, http://links.lww.com/WNL/A116) showed random multifocal movements involving the patient's trunk and limbs. These movements were predominantly nonrhythmic, nonstereotyped, nonsynchronous, and flowing in nature but also with superimposed jerky movements giving rise to an appearance of restlessness. During tongue protrusion, she demonstrated motor impersistence, ${ }^{1}$ which is the inability to sustain persistent muscle contractions. These movements were worse during speech and motor tasks. There were no muscle spasms, abnormal posturing, rhythmic movements, dysmetria, or dysdiadochokinesia. Cranial nerves, motor strength, deep tendon reflexes, and sensory examination results were normal. She walked with a narrow base. General physical examination was unremarkable.

\section{Questions for consideration:}

1. What is the phenomenology of the involuntary movement?

2. What is the differential diagnosis?

3. Which tests should be obtained?

\section{GO TO SECTION 2}

From the College of Medicine (M.R.B.) and Department of Neurology (A.J.E.), University of Cincinnati; and Division of Human Genetics (E.G.W.) and Division of Neurology (S.W.W.), Cincinnati Children's Hospital Medical Center, $\mathrm{OH}$.

Go to Neurology.org/N for full disclosures. Funding information and disclosures deemed relevant by the authors, if any, are provided at the end of the article. 


\section{SECTION 2}

The patient's hyperkinetic movement was consistent with chorea with relatively minor superimposed myoclonus. Chorea, the predominant phenotype, is an involuntary hyperkinetic movement disorder characterized by irregular, nonrhythmic, nonsynchronous, flowing movements that appear restless. ${ }^{1}$ Phenomenologically, athetosis, chorea, and ballism exist on a spectrum and are differentiated based on speed, amplitude, and distribution. ${ }^{1}$

The differential diagnosis for childhood chorea is broad. Etiology can be primary (hereditary, often insidious onset) or secondary (acquired, acute, or subacute onset). Although Sydenham chorea is the most common form of acquired chorea in children, ${ }^{2}$ early-infancy onset made this condition and other pediatric autoimmune chorea disorders (e.g., systemic lupus erythematosus, antiphospholipid antibody syndrome, anti-NMDAR encephalitis) less likely. ${ }^{2}$

The persistence of chorea into the teen years ruled out physiologic chorea of infancy, and the continuous symptom ruled out paroxysmal dyskinesia. Furthermore, the medication history ruled out an iatrogenic etiology. A normal noncontrast brain MRI excluded structural abnormalities, such as prenatal or perinatal brain injury or brain malformation.
Family history suggested an autosomal dominant inheritance pattern. Normal caudate size on MRI excluded juvenile-onset Huntington disease, which would have more likely presented with a hypokinetic phenomenology. Given the patient's nonprogressive course and family history, benign hereditary chorea (BHC) was the most plausible syndromic diagnosis. Mutations in 3 genes have been identified as pathogenic. NKX2-1 mutations are associated with developmental delay, learning difficulties, hypotonia, variable hypothyroidism, pituitary involvement (empty sella syndrome), and history of neonatal respiratory distress. ${ }^{3}$ ADCY5 gene mutations have been recently recognized as a relatively common etiology of BHC. ${ }^{4}$ Finally, de novo dominant mutations in PDE10A also cause BHC but with bilateral striatal lesions. ${ }^{5}$ Both NKX2-1and ADCY5-related BHC can also include additional abnormal movements such as dystonia and myoclonus. ${ }^{3,4}$

Given these genetic considerations, thyroid function laboratory tests were ordered and revealed elevated thyroid-stimulating hormone ranging from 4.76 to 8.68 (normal range $0.53-4.00$ $\mu \mathrm{IU} / \mathrm{mL}$ ), increasing the likelihood of a pathogenic NKX2-1 mutation. Sanger sequencing analysis of the NKX2-1 gene, however, did not reveal any pathogenic variation.

\section{Questions for consideration:}

1. What other tests would you order?

2. What are management options?

GO TO SECTION 3 


\section{SECTION 3}

Given the patient's GDD/ID history, high-resolution chromosomal karyotyping was performed, which identified an inversion in chromosome 14 (46,XX,inv[14][q13q21]). The American Academy of Neurology published a practice guideline on the genetic workup of children with GDD/ID. ${ }^{6}$ After detailed history and examination, it recommended obtaining karyotype, microarray, or fluorescence in situ hybridization (FISH) studies, with rates of abnormality in nonsyndromic GDD/ID children of $>4 \%, 7.8 \%$, and $3.5 \%$, respectively. ${ }^{6}$

One of this patient's chromosomal inversion breakpoints was in the $14 \mathrm{q} 13$ region, which is in the approximate location of the NKX2-1 gene. Her early-onset nonprogressive generalized chorea associated with thyroid dysfunction strongly argued in favor of NKX2-1-related BHC. Parental testing was not possible to determine if this inversion was de novo or inherited from her symptomatic father. Subsequent Sanger sequencing of NKX2-1 was negative. However, this testing methodology only examines the exons and is not designed to detect chromosomal rearrangements. As a result, this negative test result did not exclude the possibility that the NKX2-1 gene was affected by this inversion. Thus, this test provided a falsenegative result. Appropriate interpretation of the separate genetic data was only possible by the proper interpretation of the historical and semiologic data.

Given the lack of disease-specific treatments, the management approach was symptom-based. Functional impairment due to chorea persisted despite occupational and physical therapies. Symptomatic treatment of chorea includes the use of benzodiazepines, agents that reduce dopaminergic transmission (dopamine receptor antagonists [neuroleptics], dopamine depleters), and select antiepileptic medications. ${ }^{3,7}$ Although the mechanism is unknown, levodopa has also been reported to be therapeutic in some patients with NKX2-1-related BHC. ${ }^{3}$ In severe cases, children may be considered for deep brain stimulation of bilateral internal globus pallidi. ${ }^{4}$ Our patient was treated with oral diazepam and fluphenazine after obtaining a baseline ECG. This combination provided satisfactory reduction in her chorea. She was also evaluated by an endocrinologist but was not placed on levothyroxine due to normal free T4 levels.

\section{DISCUSSION}

This report highlights (1) a case of early-onset benign hereditary chorea demonstrating normal Sanger sequencing result and (2) the importance of clinical expertise in understanding and interpreting negative or ostensibly noncontributory genetic test results.

Identifying the phenomenology of a movement disorder requires a systematic approach in history-taking, observation, and examination techniques. In our case, identifying the abnormal movement as chorea rather than dystonia or tremor helped guide the diagnostic workup and helped resolve a negative result. Unlike the nonpatterned, flowing nature of chorea, tremor is rhythmic and stereotyped whereas dystonia is tonic, with or without a jerky tremulous component. ${ }^{1}$

Once the movement phenomenology is identified, unraveling the etiology is guided by detailed history and examination. As discussed in Section 2, the age at onset, evolution of symptoms, associated symptoms, and exacerbating/relieving factors can help narrow the differential diagnosis. Other non-neurologic medical and family history may also be crucial.

As technologies advance, the approach to genetic workup requires the understanding of test limitations. ${ }^{8}$ This is important for counseling the patient and family when any test is being considered. Equally important is the interpretation of the test results. Prior documented cases of NKX2-1-related BHC have arisen from deletions, frameshift, nonsense, and missense mutations. ${ }^{3,9}$ In this case, the combination of chorea and hypothyroidism supports the likelihood of NKX2-1-related BHC especially since the identified balanced chromosomal inversion is in the region of the NKX2-1 gene. Based on available laboratory data, we do not know the precise locations of the inversion breakpoints, therefore we cannot definitively prove that this gene was affected. Theoretically an examination of NKX2-1 protein expression in affected tissues could prove that this inversion was indeed causative, although such research-based tool was not available for clinical use. Interestingly, a previously published case involves the deletion of 14q13.1-q13.3 but with intact exons and splice site junctions of the NKX2-1 gene. ${ }^{10}$ This patient presented with neonatal respiratory distress, recurrent respiratory infections, chorea, and hypothyroidism, consistent with clinical diagnosis of NKX2-1-related BHC. Sanger sequencing would not have identified either of these cases. Similarly, microarray analysis and whole exome sequencing could not have identified a chromosomal inversion, such as in this patient. FISH can identify a chromosomal inversion but requires a high index of suspicion for the genetically abnormal region thought to be involved.

In this patient with an autosomal-dominant, generalized nonprogressive chorea and thyroid dysfunction, the pretest probability for an NKX2-1 gene mutation was high. Although Sanger sequencing was negative, the appropriate interpretation of the subsequent karyotype, undertaken in view of the patient's cognitive history, identified an abnormality in the region where the suspected etiologic NKX2-1 gene resides, thus circuitously confirming the genetic etiology of this patient's $\mathrm{BHC}$ phenotype. Understanding the limitation of Sanger sequencing and recognizing the clinical features of NKX2-1-related disorder allowed the appropriate interpretation of her chromosome 14q13q21 inversion.

\section{Author contributions}

M.R.B., A.J.E., and S.W.W.: design of the study, drafting and revision of the manuscript for intellectual content. E.G.W.: manuscript revision.

\section{Study funding}

There was no external funding or sponsorship for this report. 


\section{Disclosure}

M.R. Basu reports no disclosures. Dr. Espay has received grant support from the NIH, Great Lakes Neurotechnologies, and the Michael J. Fox Foundation; personal compensation as a consultant/scientific advisory board member for AbbVie, TEVA, Impax, Merz, Acadia, Cynapsus/Sunovion, Lundbeck, and USWorldMeds; publishing royalties from Lippincott Williams \& Wilkins, Cambridge University Press, and Springer; and honoraria from AbbVie, UCB, USWorldMeds, Lundbeck, Acadia, the American Academy of Neurology, and the Movement Disorders Society. He serves as Associate Editor of the Journal of Clinical Movement Disorders and on the editorial board of Parkinsonism and Related Disorders. E.G. Wakefield reports no disclosures. Dr. Wu receives support from NIH and Tourette Association of America and is the site principal investigator for EryDel SpA-sponsored clinical trial for Ataxia-Telangiectasia. Go to Neurology.org/ $\mathrm{N}$ for full disclosures.

\section{References}

1. Sanger TD, Chen D, Fehlings DL, et al. Definition and classification of hyperkinetic movements in childhood. Mov Disord 2010;25:1538-1549.

2. Cardoso F. Autoimmune choreas. J Neurol Neurosurg Psychiatry 2017;88:412-417.

3. Patel NJ, Jankovic J. NKX2-1-related disorders. In: Pagon RA, Adam MP, Ardinger $\mathrm{HH}$, et al, eds. GeneReviews. Seattle: NCBI: 1993.

4. Dy ME, Chang FC, Jesus SD, et al. Treatment of ADCY5-associated dystonia, chorea, and hyperkinetic disorders with deep brain stimulation: a multicenter case series. J Child Neurol 2016;31:1027-1035.

5. Mencacci NE, Kamsteeg EJ, Nakashima K, et al. De novo mutations in PDE10A cause childhood-onset chorea with bilateral striatal lesions. Am J Hum Genet 2016;98: 763-771.

6. Michelson DJ, Shevell MI, Sherr EH, Moeschler JB, Gropman AL, Ashwal S. Evidence report: genetic and metabolic testing on children with global developmental delay: report of the Quality Standards Subcommittee of the American Academy of Neurology and the Practice Committee of the Child Neurology Society. Neurology 2011;77:1629-1635.

7. Hermann A, Walker RH. Diagnosis and treatment of chorea syndromes. Curr Neurol Neurosci Rep 2015;15:514.

8. Katsanis SH, Katsanis N. Molecular genetic testing and the future of clinical genomics. Nat Rev Genet 2013;14:415-426.

9. de Filippis T, Marelli F, Vigone MC, Di Frenna M, Weber G, Persani L. Novel NKX21 frameshift mutations in patients with atypical phenotypes of the brain-lung-thyroid syndrome. Eur Thyroid J 2014;3:227-233.

10. Barnett CP, Mencel JJ, Gecz J, et al. Choreoathetosis, congenital hypothyroidism and neonatal respiratory distress syndrome with intact NKX2-1. Am J Med Genet A 2012; 158A:3168-3173. 


\section{Neurology}

Clinical Reasoning: Importance of clinical phenomenology in the era of genetic testing Meera R. Basu, Alberto J. Espay, Emily G. Wakefield, et al.

Neurology 2018;90;e534-e537

DOI 10.1212/WNL.0000000000004930

This information is current as of February 5, 2018

Updated Information \&
Services

References

Subspecialty Collections

Permissions \& Licensing

Reprints including high resolution figures, can be found at: http://n.neurology.org/content/90/6/e534.full

This article cites 9 articles, 2 of which you can access for free at: http://n.neurology.org/content/90/6/e534.full\#ref-list-1

This article, along with others on similar topics, appears in the following collection(s):

\section{Chorea}

http://n.neurology.org/cgi/collection/chorea

Chromosomes

http://n.neurology.org/cgi/collection/chromosomes

Clinical neurology examination

http://n.neurology.org/cgi/collection/clinical_neurology_examination

Developmental disorders

http://n.neurology.org/cgi/collection/developmental_disorders

Information about reproducing this article in parts (figures,tables) or in its entirety can be found online at:

http://www.neurology.org/about/about_the_journal\#permissions

Information about ordering reprints can be found online:

http://n.neurology.org/subscribers/advertise

Neurology ${ }^{\circledR}$ is the official journal of the American Academy of Neurology. Published continuously since 1951, it is now a weekly with 48 issues per year. Copyright () 2018 American Academy of Neurology. All rights reserved. Print ISSN: 0028-3878. Online ISSN: 1526-632X.

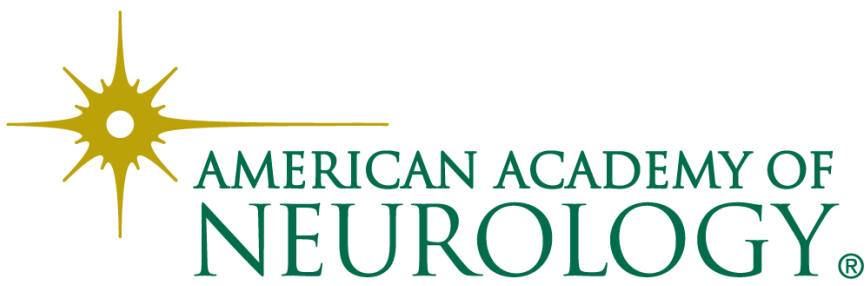

